\title{
Approaches to Assessing Burden in Caregivers of Patients with Cirrhosis
}

\author{
Beshoy Yanny ${ }^{1}$, Nguyen V. Pham ${ }^{2}$, Hussein Saleh ${ }^{2}$ and Sammy Saab*1,2 \\ ${ }^{1}$ Department of Medicine, University of California at Los Angeles, CA, USA; ${ }^{2}$ Department of Surgery, University of California \\ at Los Angeles, CA, USA
}

\begin{abstract}
Background and Aims: Being a caregiver for a patient with chronic liver disease (CLD) can be burdensome mentally, emotionally financially, and physically. The aim of this study was to systemically review the available tools and propose tools that can comprehensively evaluate caregiver burden for individuals caring for patients with CLD. Methods: We searched the PubMed database for all studies on the impact of patients with CLD on caregiver burden without timeframe restriction. Eligible studies included cohort studies, review studies, or cross-sectional studies. The number of patients and caregivers was isolated from each paper. Studies in the same categories were isolated and statistically compared. Results: A total of 13 studies meeting our inclusion criteria as stated in the methods sections were included. In total, 2528 caregivers were taking care of 2003 patients with CLD. Women made up the majority of caregivers at $78.2 \%$, $95.7 \%$ of whom identified as the patient's spouse. Caregiver strain index is one of the most comprehensive tools; however, the questions are very general and do not fully elucidate financial strain. Beck depression and anxiety were correlated $(p=0.0001)$, and both depression and anxiety were correlated with perceived caregiver burden (PCB) and Zarit Burden Interview (ZBI) $(p=0.002)$. Depression scale correlated with Interpersonal Support Evaluation - Short Form, and Model for End-Stage Liver Disease score correlated with ZBI and PCB (total and in most domains; $p=0.001$ ). Patient's poorer cognitive performance correlated with higher ZBI and PCB (employed patients had higher cognitive performance and lower ZBI and PCB). Conclusions: Caregiver burden remains poorly understood due to the lack of uniformity in the assessment tools used to evaluate caregiver burden. None of the tools used to evaluate caregiver burden are comprehensive;
\end{abstract}

Keywords: Caregiver burden in liver disease; Liver cirrhosis; Liver transplant. Abbreviations: AUDIT, alcohol use disorders identification test; BDI-II, Beck depression inventory-II; CLD, chronic liver disease; HADS-A, hospital anxiety and depression scale-anxiety; HADS-D, hospital anxiety and depression scaledepression; $\mathrm{HCC}$, hepatocellular carcinoma; HRQOL, health-related quality of life; ISEL-SF, interpersonal support evaluation - short form; LT, liver transplant; MCS, mental component summary; MCSDS, Marlowe Crowne social desirability scale; MELD, model for end-stage liver disease; NAFL, non-alcoholic fatty liver disease; PBC, primary biliary cirrhosis; PCB, perceived caregiver burden; PCRS, Picot caregiver reward scale; PCS, physical component summary; QOL, quality of life; SD, standard deviation; STAI, state trait anxiety information; ZBI, Zarit burden interview; ZBI-SF, Zarit burden interview - short form.

Received: 9 November 2019; Revised: 12 February 2020; Accepted: 15 March 2020

*Correspondence to: Sammy Saab, Pfleger Liver Institute, UCLA Medical Center, 200 Medical Plaza, Suite 214, Los Angeles, CA 90095, USA. Tel: +1-310-2066705, Fax: +1-310-206-4197, E-mail: SSaab@mednet.ucla.edu however, most tools correlate statistically in the ability to identify caregiver burden. A comprehensive tool is lacking for identifying caregiver burden in patients with CLD.

Citation of this article: Yanny B, Pham NV, Saleh H, Saab S. Approaches to assessing burden in caregivers of patients with cirrhosis. J Clin Transl Hepatol 2020;8(2):127-134. doi: $10.14218 /$ JCTH.2019.00054.

\section{Introduction}

Liver disease causes approximately 2 million deaths per year worldwide. ${ }^{1,2}$ In the USA, liver disease is the twelfth most common cause of mortality. ${ }^{1,2}$ Approximately 34,000 deaths are reported annually from liver cirrhosis. ${ }^{3}$ Liver transplant (LT) has dramatically improved survival and quality of life (QOL) for patients with complicated liver disease..$^{1,2}$ Transplant is a life-altering change for the patient and their families. The process of LT evaluation is long and stressful. Patients' families provide care and support for their loved ones mentally, emotionally, medically, and financially. Research shows that family support is essential for a good LT outcome. ${ }^{4}$

The LT waitlist contains approximately $16,000-17,000$ patients awaiting transplantation. ${ }^{5}$ All patients on this waitlist undergo a social evaluation and should have family members who are willing to be fulltime caregivers during the transplant process and after $\mathrm{LT}$, as required by most transplant centers in the USA. Caregivers play an important role in a transplant patient's health care during the whole process and particularly recovery. Having a responsible caregiver can strengthen the information relayed to the patients and effectively help them with treatment, ultimately improving LT outcomes and compliance.

Accordingly, caregivers for LT recipients play a critical role in the pre- and post-LT stages. Previous studies have shown that a poor caregiver QOL predicts that a $\mathrm{LT}$ recipient will receive low quality care by their caregiver. ${ }^{1,2,6}$ Furthermore, caregivers with a heavy financial burden have a poorer QOL, which leads to less optimal care delivery for the LT recipient. ${ }^{1,2}$ The focus during the LT evaluation process is often shifted to the individual receiving the transplant. The caregiver assessment often stops after ensuring that a dedicated caregiver and possibly a secondary caregiver will be present to help the LT recipient. Most transplant centers do not assess caregivers' QOL or other burdens such as mental, physical, psychological and financial despite their proven role in providing a good post-LT outcome to their loved ones who have received a $\mathrm{LT}^{1}{ }^{1}$ Therefore, this study focuses on caregiver 
burden, and tools available to the clinician and transplant center to evaluate the burden.

In this systemic review, we evaluated caregiver burden assessment tools available to the clinician by reviewing the available literature specifically for individuals with chronic liver disease (CLD), and compared the tools utilized. We identified the most appropriate tools in each category including mental, emotional, financial, and physical, and proposed a combination of tools that can comprehensively evaluate caregiver burden for individuals caring for patients with CLD.

\section{Methods}

\section{Search strategy and identification of studies}

We searched the MEDLINE database for all studies on the impact of patients with CLD on caregiver burden without timeframe restriction. We used a combination of keywords 'caregiver,' 'care giving,' 'informal care,' 'caretaker,' 'family,' 'spouse,' 'parents,' 'friends,' 'mother,' 'father,' 'liver cirrhosis,' 'liver,' 'liver disease,' 'cirrhosis,' 'chronic liver disease,' and 'PBC.' Bibliographies of all identified studies were searched for relevant articles for additional studies. We also searched additional electronic databases such as ProQuest.

\section{Inclusion and exclusion criteria}

We included all studies published in scientific journals that investigated burden experienced by individuals who are caregivers for patients with CLD or cirrhosis, or who are on the LT waitlist. As our study attempted to assess all available information on caregiver's burden as a result of caring for adult patient with liver disease, studies whose source populations were above 18 years of age and resided in or outside the USA, and studies published in English were included. We included studies that used a quantitative method of analysis to describe the burden of caregiving, mental health outcomes of caregivers, and their QOL. Studies that only used qualitative interview-based instruments were excluded from our review. The inclusion criteria were: all studies published in scientific journals that investigated burden experienced by caregivers of patients with CLD, cirrhosis, or who are on the LT waitlist; peer-reviewed articles in English and a full-text version of the study available; source populations residing in or outside the USA; source populations only including adult patients and caregivers (18 years old or above); patients diagnosed with CLD, cirrhosis of any etiologies, or who are on the LT waitlist; and studies that used a quantitative method of analysis to describe burden of caregiving or mental health (stress, distress, depression, anxiety) of caregivers or QOL or a combination of these outcomes. We excluded the following: experimental trial study design, systemic review, dissertations/theses, published abstracts, studies published in language other than English leading to unavailable full-text articles, patient population or caregiver population $<18$ years of age, patient population with primary diagnosis other than CLD, cirrhosis, or not on the LT waitlist such as hepatocellular carcinoma, non-alcoholic fatty liver disease, post-LT studies, studies that investigated caregivers impacted by their own liver disease, and studies that only utilized a qualitative interview-based instrument to assess caregiver's burden (qualitative methodology).

\section{Caregiver's burden definition}

The definition of caregiver's burden has been a topic of ongoing discussion. Caregiver's burden is defined as the impact of caregiving on caregiver's perceived emotion, physical health, social life, and finance over time. ${ }^{7,8}$ There have been attempts to distinguish caregiver's burden into subjective and objective burdens. ${ }^{9,10}$ Subjective burden refers to caregivers' reflection on their caregiving experience through their attitude, emotion, awareness, perception, and affective orientation. ${ }^{9}$ Objective burden reflects the disruptions of caregivers' physical health, household, financial status, and other aspects of life that are the results of caregiving.

\section{Caregiver assessment tools}

Zarit burden interview - Short form (ZBI-SF): This 12item self-reported instrument assesses caregiver's burden with a total score of 48 . It is a shortened version of the 22item Zarit Burden Scale. Higher score indicates higher caregiver burden. This tool focuses on time schedule, physical health, mental and psychosocial burden. ${ }^{1,11,12}$

Zarit burden scale: This 22-item self-reported instrument assesses caregiver's burden with each item on a 9point rating scale. A rating of 9 for each item indicates a higher level of burden. The scale measures physical, emotional, and financial toll of providing care. This also focuses on time schedule, physical health, mental and psychosocial burden. ${ }^{13}$

Health-related QOL: This 136-item questionnaire used to assess patient's physical, psychosocial, and general health outcomes. It has two overall domains: physical and psychosocial; 12 subcategories: sleep and rest, eating, work, home management, recreation and pastimes, ambulation, mobility, body care and movement, social interaction, alertness behavior, emotional behavior, communication. Higher score indicates a poorer level of health. ${ }^{11,14}$

Perceived caregiver burden scale (PCB): This 31 item self-reported questionnaire assesses perceived caregiver's burden with five domains: impact on finances, impact on schedule, sense of abandonment, impact on health, sense of entrapment. A higher score indicates a higher level of perceived burden. Although brief, this tool asks questions regarding physical health, mental health, social situation, finance, and sleep. ${ }^{15}$

Caregiver strain index: This 13 -item questionnaire to assess caregiver burden. Higher scores mean more strain. If caregiver answers "yes" to seven or more items, clinically significant caregiver strain is indicated. This briefly asks about time schedule, physical health, mental health, finance, and sleep. We suggest this tool be used as a pathway to determine the reason for the patient's caregiver's most serious concern, and based on the concern, another in depth tool may be utilized to further evaluate the burden. ${ }^{16,17}$

Caregiver benefit index: This index examines benefits perceived by transplant caregivers in 12 areas. Higher scores mean more benefits. Questions focus on benefit gained from helping patient, spending time with patients, personal growth, and interpersonal benefits. ${ }^{16,18}$

\section{Results}

A total of 13 studies meeting our inclusion criteria as stated in the Methods section were included (Fig. 1)..$^{7-10,12-13,16,19-24}$ 
A total of 2528 caregivers were taking care of 2003 patients with CLD. Women made up the majority of caregivers at $78.2 \%$, of whom $95.7 \%$ identified as the patient's spouse. Overall caregiver burden fell on $73.5 \%$ of spouses, parents made up $12.7 \%$ of the caregiver cohort, $3.2 \%$ were children, and $10.5 \%$ fell into the 'other' relationship category. The cumulative mean ( \pm standard deviation $[S D]$ ) age of the caregiver was 52.7 ( \pm 7.2 ) years. Unemployed caregivers made up $65.2 \%$ of the caregiver cohort. Viral hepatitis contributed to $54.3 \%$ of patients being cared for by a caregiver, alcoholic liver disease made up $23 \%$, non-alcoholic steatohepatitis was $12.7 \%$ and $10 \%$ contributed to other liver diseases.

Patients on the LT list made up $20.1 \%$ of the entire cohort included in this systemic review. ${ }^{7-10,12-13,16,19-24}$ None of the tools were incorporated during the LT evaluation to aid in determining outcomes. Caregiver burden was highest in those taking care of patients on the LT list with a mean ( \pm SD) Zarit burden assessment score of 14.8 ( \pm 1.01 ). PCB and ZBI were correlated $(p=0.0001) .^{7-10,12-13,16,19-24}$
Beck depression and anxiety were correlated $(p=0.0001)$, depression and anxiety both correlated with PCB and ZBI $(p=0.004)$, the depression scale correlated with the Interpersonal Support Evaluation - Short Form, and Model for EndStage Liver Disease (MELD) score correlated with ZBI and PCB (total and in most domains; $p=0.002$ ). Patient's poorer cognitive performance correlated with higher ZBI and PCB (employed patients had a higher cognitive performance and lower ZBI and PCB).

The largest study evaluated seven caregiver assessment tools, ${ }^{11}$ and the smallest two tools. ${ }^{19}$ The number of unique tools identified and used in the different studies was 27. Select studies that validated and utilized the instruments are shown Table. ${ }^{25-48}$ The mean ( \pm SD) number of assessment tools used was $3.42( \pm 1.7)$. The most commonly used caregiver burden assessment tool used in the studies was the Zarit Burden score assessment, which was used in $77 \%$ of the studies looking into caregiver burden. ${ }^{1,2,4,12,13}$ BDI-II: 21item validated questionnaire assessing depression was used

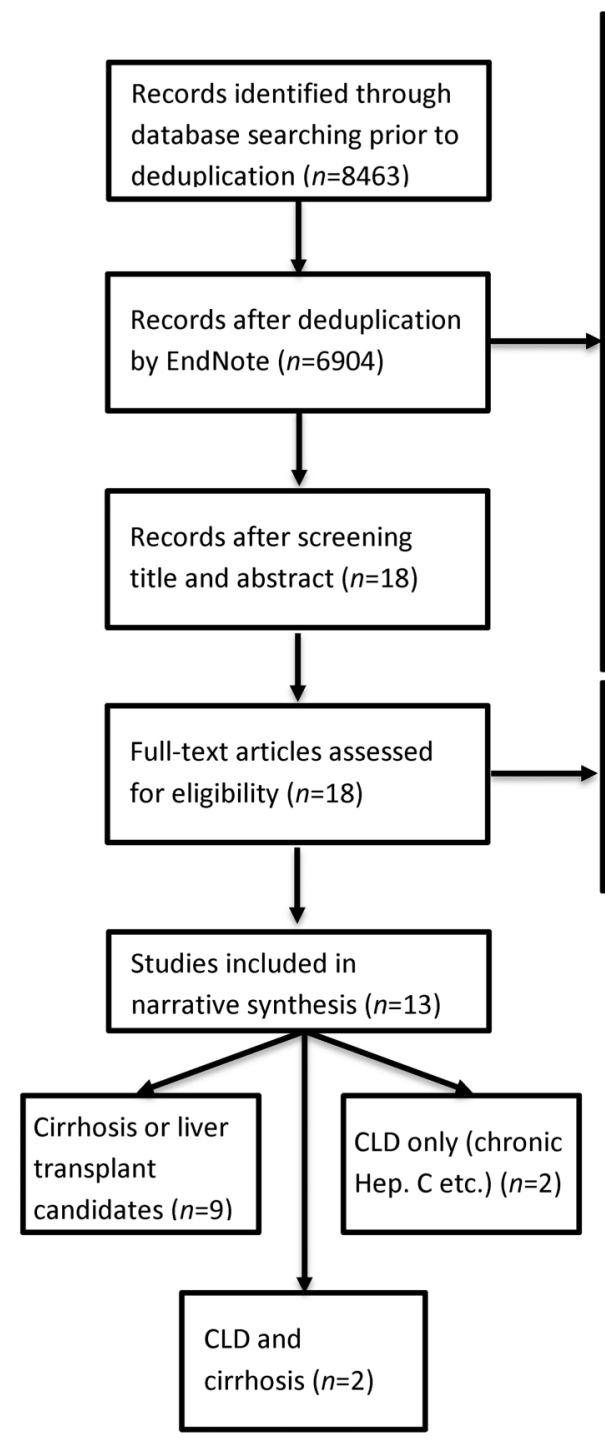

Screened Records excluded for the following

reasons: $(n=6886)$

- Irrelevant title or abstract or studies do not evaluate caregiver's burden or mental health status as a result of caregiving

- Patients are Post liver transplant recipients

- Patients or caregivers $<18$ years of age

- Studies investigate caregivers impacted by their own liver disease

- Studies in which patient's primary disease is not cirrhosis, CLD or patients are not on liver transplant waitlist

- Books, non-journal articles, Systemic review, dissertations/theses, abstracts, case study, study design reports or studies that are not primary articles

- Studies published in language other than English

Full text articles excluded $(n=5)$ :

- Studies utilize only qualitative instruments $(n=2)$

- Study does not have full text available for review $(n=3)$

Fig. 1. Methods utilized to isolate the included articles. 
Yanny B. et al: Liver Disease Caregiver Burden

Table 1. Tools studied in the evaluation of caregiver burden in patients with chronic liver disease

\begin{tabular}{|c|c|}
\hline Instrument (validation studies) & Description (selected studies utilized the instrument) \\
\hline Perceived caregiver burden scale ${ }^{15}$ & $\begin{array}{l}31 \text {-item self-reported questionnaire assesses perceived caregiver's burden with } \\
5 \text { domains: impact on finances, impact on schedule, sense of abandonment, impact } \\
\text { on health, sense of entrapment. A higher score indicates a higher level of perceived } \\
\text { burden. }{ }^{1,11}\end{array}$ \\
\hline Zarit burden interview - short form ${ }^{12}$ & $\begin{array}{l}\text { 12-item self-reported instrument assesses caregiver's burden with total score of } \\
48 \text {. It is a shortened version of the } 22 \text {-item Zarit Burden Scale. Higher score } \\
\text { indicates higher burden., } 11\end{array}$ \\
\hline Zarit Burden Scale ${ }^{13}$ & $\begin{array}{l}22 \text {-item self-reported instrument assesses caregiver's burden with each item on a } \\
9 \text {-point rating scale. A rating of } 9 \text { for each item indicates higher level of burden. The } \\
\text { scale measures physical, emotional, and financial toll of providing care. }{ }^{4,12}\end{array}$ \\
\hline Beck depression inventory (BDI-II) ${ }^{23}$ & $\begin{array}{l}21 \text {-item validated instrument assesses depression (including attitude, depressive } \\
\text { symptoms, and suicidal ideation). Each item is rated on a scale of } 0 \text { to } 3 \text {. The cutoff } \\
\text { scores are: }<11 \text {, minimal depression; } 12 \text { to } 19 \text {, mild to moderate depression; } 20 \text { to } \\
35 \text {, moderate depression; and } 36 \text { to } 63 \text {, severe depression. } 11,14,16\end{array}$ \\
\hline Beck Anxiety Inventory ${ }^{24}$ & $\begin{array}{l}21 \text {-item validated instrument assesses anxiety. Score } 0 \text { to } 21 \text { indicates mild to very } \\
\text { low anxiety; score } 22 \text { to } 35 \text { indicates moderate anxiety; score above } 36 \text { indicates } \\
\text { severe anxiety. }{ }^{1,11}\end{array}$ \\
\hline $\begin{array}{l}\text { Interpersonal support evaluation list - } \\
\text { short form inventory }{ }^{28}\end{array}$ & $\begin{array}{l}\text { 16-question validated questionnaire assesses level of social support perceived by } \\
\text { caregiver. Each question has } 2 \text { answer options, "probably false" or "probably true." } \\
\text { Higher score is worse. }{ }^{1}\end{array}$ \\
\hline Pittsburgh sleep quality index ${ }^{29}$ & $\begin{array}{l}24 \text {-item questionnaire assesses quality of sleep and sleep disturbances over } \\
1 \text { month. } 19 \text { questions are self-reported and } 5 \text { are rated by bed partner or } \\
\text { roommate. There are } 7 \text { component scores: subjective sleep quality, sleep latency, } \\
\text { sleep duration, habitual sleep efficiency, sleep disturbances, use of sleeping } \\
\text { medication, daytime dysfunction and a global score. Higher score indicates worse } \\
\text { quality of sleep or higher sleep disturbance. }{ }^{11}\end{array}$ \\
\hline Epworth sleepiness scale ${ }^{30}$ & $\begin{array}{l}\text { 8-item questionnaires on a 4-point scale with score ranging from } 0 \text { to } 24 \text { assessing } \\
\text { daytime sleepiness. The higher the score means the higher the person's daytime } \\
\text { sleepiness. }{ }^{11}\end{array}$ \\
\hline HRQOL: sickness impact profile ${ }^{14}$ & $\begin{array}{l}136 \text {-item questionnaire used to assess patient's physical, psychosocial, and } \\
\text { general health outcomes. It has } 2 \text { overall domains: physical and psychosocial; } \\
12 \text { subcategories: sleep and rest, eating, work, home management, recreation and } \\
\text { pastimes, ambulation, mobility, body care and movement, social interaction, } \\
\text { alertness behavior, emotional behavior, communication. Higher score indicates a } \\
\text { poorer level of health. }{ }^{11}\end{array}$ \\
\hline Medical outcomes Study SF-36 31 & $\begin{array}{l}36 \text { questions assessing } 8 \text { domains of health including physical functioning, bodily } \\
\text { pain, role limitations due to physical condition, role limitations due to emotional } \\
\text { health, social functioning, energy/fatigue, emotional well-being, and general health } \\
\text { perceptions. Mean score is compared to national norms. }{ }^{4}\end{array}$ \\
\hline $\begin{array}{l}\text { Center for epidemiological studies } \\
\text { depression } \text { scale }^{32}\end{array}$ & $\begin{array}{l}20 \text {-item scale used to measure extents of depressive symptoms experienced by } \\
\text { caregivers. Score of } 0 \text { to } 15 \text { indicates no depressive symptoms; } 16 \text { to } 20 \text { indicates } \\
\text { mild distress; } 21 \text { to } 30 \text { indicates moderate distress; } 31 \text { and higher indicates severe } \\
\text { distress. }{ }^{12,15}\end{array}$ \\
\hline Hamilton anxiety rating scale ${ }^{33}$ & $\begin{array}{l}\text { Self-report instrument with } 14 \text { items, each on a 5-point scale from } 0 \text { to } 4 \text {, assess } \\
\text { level of anxiety. A score of } 18 \text { indicates mild anxiety, a score of } 25 \text { indicates } \\
\text { moderate anxiety, and a score of } 30 \text { is severe anxiety. }{ }^{12}\end{array}$ \\
\hline $\begin{array}{l}\text { Alcohol use disorders identification } \\
\text { test }^{34}\end{array}$ & $\begin{array}{l}\text { 10-item screening tool assesses alcohol intake, use frequency, dependency, and } \\
\text { problems caused by drinking. The AUDIT distinguishes between at-risk users and } \\
\text { alcohol-dependent users. }{ }^{12}\end{array}$ \\
\hline Picot caregiver reward scale $\mathrm{e}^{35}$ & $\begin{array}{l}25 \text {-item self-report scale assesses caregiver's perceived rewards. The PCRS } \\
\text { measures pleasures, satisfactions, good feelings, and positive consequences } \\
\text { connected to caregiving responsibilities. Scores range from } 0 \text { to } 64 \text {, with higher } \\
\text { scores indicating greater perceived reward. }{ }^{12}\end{array}$ \\
\hline
\end{tabular}


Yanny B. et al: Liver Disease Caregiver Burden

Table 1. (continued)

\begin{tabular}{|c|c|}
\hline Instrument (validation studies) & Description (selected studies utilized the instrument) \\
\hline Hospital anxiety and depression scale ${ }^{36}$ & $\begin{array}{l}\text { 14-item measure assesses anxiety and depression. A 4-point severity scale is used } \\
\text { for each item. The HADS has two subscales, anxiety (HADS-A) and depression } \\
\text { (HADS-D). Scores higher than or equal to } 11 \text { on either scale indicate a definitive } \\
\text { anxiety and/or depression. }{ }^{13,17,18}\end{array}$ \\
\hline $\begin{array}{l}\text { Caregiver burden scale (Brazilian } \\
\text { version) })^{37}\end{array}$ & $\begin{array}{l}22 \text { questions used to assess caregiver's burden with } 5 \text { subscales: general strain, } \\
\text { isolation, disappointment, emotional entanglement, environment. Higher scores } \\
\text { indicate higher burden. }\end{array}$ \\
\hline $\begin{array}{l}\text { Inventario de sintomas de stress para } \\
\text { adultos de Lipp }\end{array}$ & $\begin{array}{l}\text { Instrument used to assess stress based on a 4-phase model and the effects of } \\
\text { stress in the somatic and cognitive domains. First phase is the alert phase; second } \\
\text { phase is the resistance phase; third phase is almost-exhaustion phase and fourth } \\
\text { phase is exhaustion phase. }\end{array}$ \\
\hline $\begin{array}{l}\text { Spielberger state trait anxiety } \\
\text { inventory-state form } \\
39\end{array}$ & $\begin{array}{l}20 \text {-item self-report measure assesses state-related anxiety. Participants rate } \\
\text { descriptive statements on their emotion with a } 4 \text {-point scale (not at all to very } \\
\text { much). Scores range from } 20-80 \text {. Higher score indicates elevated anxiety. } \\
\text { Normative data are used to categorize clinically elevated anxiety (STAI }>48 \text { ). }\end{array}$ \\
\hline Medical coping modes questionnaires ${ }^{40}$ & $\begin{array}{l}\text { 20-item self-report questionnaire assesses coping mechanism of caregivers among } \\
4 \text { categories: resignation, avoidance, social support seeking, information seeking. } \\
\text { A 5-point scale is used to rate each item. Higher scores indicate higher use of each } \\
\text { coping mechanism. }\end{array}$ \\
\hline
\end{tabular}

Scale for caregiver burden ${ }^{44}$

20-item self-report questionnaire measures objective and subjective burden. 10 items measure objective burden which reflects the amount of practical caregiving based on severity of patient's condition and functional needs. 10 items measure subjective burden which reflects caregiver's perceived distress due to caregiving tasks and quantity of caregiving activities. Scores range from 0 to 40 for each subscale with higher scores indicating more burden.

Marlowe Crowne social desirability scale-short form ${ }^{45}$

13 scored items separated into 2 sets measure an individual's level of socially acceptable and/or unrealistic responses. The scale assesses the degree to which participants providing responses that are favored by others such as over reporting positive attributes or underreporting negative attributes. Score range from 0 to 13 with higher scores indicating higher level of socially desirable responding.

Normative data is used to classify individuals who respond in often unrealistic, socially desirable way (MCSDS >7).

SD-36v2 health survey ${ }^{46,47}$

Measures Quality of Life (QOL) by assessing perceptions of health in eight domains: physical functioning, role functioning-physical, role functioning-emotional, vitality, pain, general health, social functioning, and mental health. Scores range from 0-100. Higher scores reflect higher QOL. SD-36 has 2 component scores - physical component summary (PCS) and mental component summary (MCS). ${ }^{19}$

Quality of life inventory ${ }^{48}$

32 statements on 16 life domains which reflect life satisfaction. 16 Life domains include health, self-esteem, goals-and-values, money, work, play, learning, creativity, helping, love relationship, friendships, relationship with children, with relatives, home, neighborhood, community. Higher scores indicate higher life satisfaction. ${ }^{19}$

Profile of mood states-short form ${ }^{49}$

Assesses mood disturbance. Caregivers read descriptive adjective and rate how they feel about them on a 5-point scale. Form provides total score and factor scores: tension-anxiety, depression-dejection, anger-hostility, vigor-activity, fatigue-inertia, confusion-bewilderment. Higher score means more mood disturbance. ${ }^{19}$

Caregiver strain index ${ }^{50}$

13-item questionnaire to assess caregiver burden. Higher scores mean more strain. If caregiver answers "yes" to 7 or more items, clinically significant caregiver strain is indicated. ${ }^{19}$

Caregiver benefit index ${ }^{30,51}$

Examines benefits perceived by transplant caregivers in 12 areas. Higher scores mean more benefits. Questions focus on benefit gained from helping patient, spending time with patients, personal growth, interpersonal benefits ${ }^{19}$

Miller social intimacy scale 52

Assesses caregiver's perceived closeness to their spouse. It provides two intimacy subscales: Frequency and Intensity and culminated in a total intimacy score. Higher score indicates greater intimacy. ${ }^{19}$ 
Yanny B. et al: Liver Disease Caregiver Burden

Table 2. Instruments used to assess rewards and benefits perceived by caregivers of patients with chronic liver disease or cirrhosis.

\begin{tabular}{|c|c|c|c|c|}
\hline $\begin{array}{l}\text { Instrument } \\
\text { (validation } \\
\text { study) }\end{array}$ & $\begin{array}{l}\text { Number } \\
\text { of items }\end{array}$ & Subscale/Domain & Score report & $\begin{array}{l}\text { Number of pre-transplant } \\
\text { caregiver administered } \\
\text { from selected studies }\end{array}$ \\
\hline $\begin{array}{l}\text { Caregiver } \\
\text { benefit } \\
\text { index }\end{array}$ & 12 & $\begin{array}{l}4 \text { benefit categories: helping the patient, } \\
\text { time with patient, self/personal growth, } \\
\text { relationship with others } \\
\text { Assess: benefits from caring, spending } \\
\text { time with patient, personal growth, } \\
\text { interpersonal benefits }\end{array}$ & $\begin{array}{l}\text { Composite score is } \\
\text { reported } \\
0 \text { to } 1 \text { scale (yes or no } \\
\text { response) used for each } \\
\text { item }\end{array}$ & $\begin{array}{l}49 \text { pre-transplant patients' } \\
\text { caregivers }\end{array}$ \\
\hline $\begin{array}{l}\text { Picot } \\
\text { caregiver } \\
\text { reward } \\
\text { scale }^{38}\end{array}$ & 25 & $\begin{array}{l}2 \text { subscales: external and Internal } \\
\text { Reward } \\
\text { Assess: perceived pleasures, } \\
\text { satisfactions, good feelings, positive } \\
\text { consequences }\end{array}$ & $\begin{array}{l}\text { Composite score is } \\
\text { reported } \\
5-\text { point scale ("Not at } \\
\text { all" to "A Great Deal") } \\
\text { used for each item }\end{array}$ & $\begin{array}{l}73 \text { caregivers of patients } \\
\text { with cirrhosis }\end{array}$ \\
\hline
\end{tabular}

in $23 \%$ of the studies; Beck Anxiety Inventory: 21 -item validated questionnaire assessing anxiety was used in $23 \%$ of the studies; Pittsburgh Sleep Quality Index: self-rated questionnaire assessing sleep quality and disturbances over a 1month interval was used in $15.3 \%$ of the studies; and Epworth Sleepiness Scale: 8-item questionnaire on a 4point scale ranging from 0 to 24 assessing daytime sleepiness was used in $15.3 \%$ of the studies. ${ }^{2,19-21,23,24,26,29,30} \mathrm{~A}$ higher score indicating a poorer level of health was used in $77 \%$ of the studies. ${ }^{20,21,25}$ Perceived Caregiver Burden: 31-item questionnaire was used in $77 \%$ of the studies. $15,16,22,25,27$

Overall, only $7.6 \%$ of the studies included a comprehensive assessment that included mental, emotional, physical, financial, and psychological. $1,2,4,16,18-22,25,27,49-52$ The study included a 20-patient caregiver dyad and used a total of seven assessment tools in order to be inclusive. Financial burden was considered in $38 \%$ of the studies and psychological in $77 \%$ of the studies, which included anxiety, depression, sleep heath, and feeling of entrapment. ${ }^{2,16,19-22,25-27,49}$ QOL was assessed in $53.8 \%$ of the studies. Caregiver burden assessed with the Zarit Burden tool with a score of 15 ( \pm 0.8$)$ posed the poorest outcomes for patients with CLD. ${ }^{1,2,4,11,19,20,21,26}$

A number of other instruments were used in assessing caregiver burden in patients with CLD (Table 1), which measured different aspects of burden in caregivers. All studies are listed in Tables 1 and 2 with references. The studies evaluated caregiver burden both in the inpatient and outpatient settings. Inpatient questionnaires were answered in $38 \%$ of the studies, and $62 \%$ evaluated the caregivers in the outpatient setting. The assessment tools were administered to patient's primary and secondary caregivers who care for patients with CLD.

\section{Discussion}

Caregivers have a critical role in the outcome and disease progression of patients with CLD. Multiple studies have shown a better outcome in patients with a responsible caregiver. ${ }^{1,2}$ The results of our systemic review revealed that there is no comprehensive way to evaluate caregiver burden via one tool. A comprehensive evaluation of caregiver burden is possible by combining multiple tools; however, this can be cumbersome as many tools have similar questions that can be redundant for the patient and family (Table 3 ). Although difficult, it is doable. Higher MELD score correlated with ZBI and PCB (total and in most domains). Patient's poorer cognitive performance correlated with higher ZBI and PCB (employed patients had higher cognitive performance and lower ZBI and PCB), and not a single tool was able to evaluate mental, physical, social, and financial burden all together. ${ }^{2}$ Our study also noted that caregivers of those who are on the transplant list have the highest caregiver burden based on ZBI and PCB score, and higher caregiver burden correlates with poor patient outcomes. Patients with a caregiver who had a ZBI score of 15.7 or higher had the poorest outcomes with increased number of hospitalizations and higher number of missed appointments, which ultimately leads to increased morbidity and mortality. Financial burden seems to have the most impact on outcomes.

LT centers do not use a caregiver burden tool and there are no cutoff values to move forward with transplant evaluation.

Table 3. Components of caregiver burden assessed by different burden instrument utilized

\begin{tabular}{lllll}
\hline & PCB & ZBI-22 & ZBI-SF & Scale for caregiver burden \\
\hline Time/schedule & $\mathrm{X}$ & $\mathrm{X}$ & $\mathrm{X}$ & \\
Physical health & $\mathrm{X}$ & $\mathrm{X}$ & $\mathrm{X}$ & $\mathrm{X}$ \\
Mental/psychosocial health & $\mathrm{X}$ & $\mathrm{X}$ & $\mathrm{X}$ & $\mathrm{X}$ \\
Finance & $\mathrm{X}$ & $\mathrm{X}$ & $\mathrm{X}$ & $\mathrm{X}$ \\
Sleep & & & $\mathrm{X}$ \\
\hline
\end{tabular}

Components of caregiver burden are selected based on established domains for each burden instrument or based on the items or questions asked. Abbreviations: PCB, perceived caregiver burden; ZBI-22, 22-item Zarit burden interview; ZBI-SF, Zarit burden interview-short form. 
The social evaluation prior to LT is a subjective evaluation in most cases. An objective measure is needed to evaluate the caregiver situation prior to moving forward with transplantation. Perhaps transplant centers should utilize caregiver burden tools more often as a standard practice in LT evaluation. However, those would be limited, as based on previous studies, in order to have a comprehensive assessment, one must use a total of seven assessment tools. This would most likely be cumbersome for the patient and family. Our study showed that the most commonly used tool for evaluating caregiver burden in patients with CLD is the Zarit caregiver burden tool.

Another suggestion is to use a general tool to evaluate what the patients' caregivers preserve as the highest burden then follow-up with a more in detail tool that correlates to the caregivers concern. A tool that is general and brief is the Caregiver Strain Index, which is a brief 13-question survey that evaluates time schedule, physical health, metal, social, finance, and sleep. Based on the answers, Table 1 may be used to hone in on a more specific tool that matches the caregivers' needs for evaluation. Table 3 includes components of caregiver burden assessed by the different burden instrument utilized.

This study is the only systemic review available with the greatest number of patients. It is limited as it is review, and there was no uniformity in the tools used by the research papers. This does not undermine the strength of the study due to number of patients included. In the future, work should be focused on developing a comprehensive tool to assess social, financial, physical, psychological burden with one tool, and incorporating the caregiver burden assessment tool into the LT evaluation process as an objective measure. The limitations of the study included the absence of an index assessment to use for comparison, which caused heterogeneity in the statistical analysis; this was balanced by the number of patients included. The abovementioned limitation does not undermine the strength of the study, which included the large number of studies and patients studied. Future research should focus on a more comprehensive tool to assess caregiver burden.

\section{Conclusions}

Caregiver burden remains poorly understood due to the lack of uniformity in the assessment tools used to evaluate caregiver burden. None of the tools used to evaluate caregiver burden are comprehensive; however, most tools correlate statistically with the ability to identify caregiver burden. A comprehensive tool is lacking for identifying caregiver burden in patients with CLD. Due to the correlation between caregiver burden and outcomes in patients with CLD, one should highly consider using a standard caregiver assessment tool in the LT evaluation process.

\section{Funding}

None to declare.

\section{Conflict of interest}

The authors have no conflict of interests related to this publication.

\section{Author contributions}

Study concept and design (SS, BY), acquisition of data (NP, $\mathrm{HS}$ ), analysis and interpretation of data (SS, BY, NP), drafting of the manuscript (BY), critical revision of the manuscript for important intellectual content (SS, BY), statistical analysis (BY, PN), obtained funding (N/A), administrative, technical, or material support, study supervision (SS).

\section{References}

[1] Bajaj JS, Wade JB, Gibson DP, Heuman DM, Thacker LR, Sterling RK, et al. The multi-dimensional burden of cirrhosis and hepatic encephalopathy on patients and caregivers. Am J Gastroenterol 2011;106:1646-1653. doi: 10.1038/ajg.2011.157.

[2] Rakoski MO, McCammon RJ, Piette JD, Iwashyna TJ, Marrero JA, Lok AS, et al. Burden of cirrhosis on older Americans and their families: analysis of the health and retirement study. Hepatology 2012;55:184-191. doi: 10 . 1002/hep. 24616

[3] Hansen L, Lyons KS, Dieckmann NF, Chang MF, Hiatt S, Solanki E, et al. Background and design of the symptom burden in end-stage liver disease patientcaregiver dyad study. Res Nurs Health 2017;40:398-413. doi: 10.1002/nur. 21807.

[4] Nguyen DL, Chao D, Ma G, Morgan T. Quality of life and factors predictive of burden among primary caregivers of chronic liver disease patients. Ann Gastroenterol 2015;28:124-129.

[5] Martin P, DiMartini A, Feng S, Brown R Jr, Fallon M. Evaluation for liver transplantation in adults: 2013 practice guideline by the American Association for the Study of Liver Diseases and the American Society of Transplantation. Hepatology 2014;59:1144-1165. doi: 10.1002/hep.26972.

[6] Wei L, Li J, Cao Y, Xu J, Qin W, Lu H. Quality of life and care burden in primary caregivers of liver transplantation recipients in China. Medicine (Baltimore) 2018;97:e10993. doi: 10.1097/MD.0000000000010993.

[7] Zarit SH, Reever KE, Bach-Peterson J. Relatives of the impaired elderly: correlates of feelings of burden. Gerontologist 1980;20:649-655. doi: 10. 1093/geront/20.6.649.

[8] Zarit SH, Zarit JM. Families under stress: Interventions for caregivers of senile dementia patients. Psychotherapy: Theory, Research \& Practice 1982;19:461-471. doi: 10.1037/h0088459.

[9] Biegel DE, Sales E, Schulz R. Family caregiving in chronic illness: Alzheimer's disease, cancer, heart disease, mental illness, and stroke. Sage Publications, Inc; 1991.

[10] Montgomery RJ, Gonyea JG, Hooyman NR. Caregiving and the experience of subjective and objective burden. 1985. doi: 10.2307/583753.

[11] Bajaj JS, Ellwood M, Ainger T, Burroughs T, Fagan A, Gavis EA, et al. Mindfulness-based stress reduction therapy improves patient and caregiverreported outcomes in cirrhosis. Clin Transl Gastroenterol 2017;8:e108. doi: $10.1038 / \operatorname{ctg} .2017 .38$

[12] Bédard M, Molloy DW, Squire L, Dubois S, Lever JA, O'Donnell M. The Zarit Burden Interview: a new short version and screening version. Gerontologist 2001;41:652-657. doi: 10.1093/geront/41.5.652.

[13] Zarit S, Orr NK, Zarit JM. The hidden victims of Alzheimer's disease: Families under stress. New York University Press; 1985.

[14] Bergner M, Bobbitt RA, Carter WB, Gilson BS. The Sickness Impact Profile: development and final revision of a health status measure. Med Care 1981; 19:787-805. doi: 10.1097/00005650-198108000-00001.

[15] Stommel M, Given CW, Given B. Depression as an overriding variable explaining caregiver burdens. J Aging Health 1990;2:81-102. doi: 10. $1177 / 089826439000200106$

[16] Rodrigue JR, Dimitri N, Reed A, Antonellis T, Hanto DW, Curry M. Quality of life and psychosocial functioning of spouse/partner caregivers before and after liver transplantation. Clin Transplant 2011;25:239-247. doi: 10. $1111 / \mathrm{j} .1399-0012.2010 .01224 . x$

[17] Robinson BC. Validation of a caregiver strain index. J Gerontol 1983;38:344348. doi: 10.1093/geronj/38.3.344.

[18] Meltzer LJ, Rodrigue JR. Psychological distress in caregivers of liver and lung transplant candidates. J Clin Psychol Med Settings 2001;8:173-180. doi: 10. 1023/A: 1011317603415

[19] Bolden L, Wicks MN. Predictors of mental health, subjective burden, and rewards in family caregivers of patients with chronic liver disease. Arch Psychiatr Nurs 2010;24:89-103. doi: 10.1016/j.apnu.2009.04.010.

[20] Miyazaki ET, Dos Santos R Jr, Miyazaki MC, Domingos NM, Felicio HC, Rocha $\mathrm{MF}$, et al. Patients on the waiting list for liver transplantation: caregiver burden and stress. Liver Transpl 2010;16:1164-1168. doi: 10.1002/lt. 22130.

[21] Bolkhir A, Loiselle MM, Evon DM, Hayashi PH. Depression in primary caregivers of patients listed for liver or kidney transplantation. Prog Transplant 2007; 17:193-198.

[22] Domínguez-Cabello E, Martín-Rodríguez A, Pérez-San-Gregorio MA, PérezBernal J. Influence of relatives' anxious symptomatology on the quality of life of pretransplant hepatic patients. Transplant Proc 2010;42:2964-2965. doi: 10.1016/j.transproceed.2010.07.059. 
[23] Beck AT, Steer RA, Ball R, Ranieri W. Comparison of Beck Depression Inventories -IA and -II in psychiatric outpatients. J Pers Assess 1996;67:588-597. doi: 10.1207/s15327752jpa6703_13.

[24] Beck AT, Epstein N, Brown G, Steer RA. An inventory for measuring clinical anxiety: psychometric properties. J Consult Clin Psychol 1988;56:893-897. doi: $10.1037 / / 0022-006 \times .56 .6 .893$.

[25] Goetzinger AM, Blumenthal JA, O'Hayer CV, Babyak MA, Hoffman BM, Ong L, et al. Stress and coping in caregivers of patients awaiting solid organ transplantation. Clin Transplant 2012;26:97-104. doi: 10.1111/j.1399-0012. 2011.01431.x.

[26] Malik P, Kohl C, Holzner B, Kemmler G, Graziadei I, Vogel W, et al. Distress in primary caregivers and patients listed for liver transplantation. Psychiatry Res 2014;215:159-162. doi: 10.1016/j.psychres.2013.08.046.

[27] Domínguez-Cabello E, Martín-Rodríguez A, Pérez-San-Gregorio MA, Fernández-Jiménez E, Sousa-Martín JM, Bernardos-Rodríguez A. Coping strategies in liver patients as a function of relatives' anxiety level. Transplant Proc 2012;44:2616-2618. doi: 10.1016/j.transproceed.2012.09.106.

[28] Cohen S, Mermelstein R, Kamarck T, Hoberman HM. Measuring the Functional Components of Social Support. In: Sarason IG, Sarason BR. (eds) Social Support: Theory, Research and Applications. NATO ASI Series. Springer, Dordrecht, 1985. doi: 10.1007/978-94-009-5115-0_5.

[29] Buysse DJ, Reynolds CF 3rd, Monk TH, Berman SR, Kupfer DJ. The Pittsburgh Sleep Quality Index: a new instrument for psychiatric practice and research Psychiatry Res 1989;28:193-213. doi: 10.1016/0165-1781(89)90047-4.

[30] Johns MW. A new method for measuring daytime sleepiness: the Epworth sleepiness scale. Sleep 1991;14:540-545. doi: 10.1093/sleep/14.6.540.

[31] Ware JE Jr, Sherbourne CD. The MOS 36-item short-form health survey (SF-36). I. Conceptual framework and item selection. Med Care 1992;30:473-483.

[32] Radloff LS. The CES-D scale: A self-report depression scale for research in the general population. Applied Psychological Mmeasurement 1977;1:385401. doi: $10.1177 / 014662167700100306$.

[33] Hamilton $\mathrm{M}$. The assessment of anxiety states by rating. $\mathrm{Br}$ ] Med Psychol 1959;32:50-55. doi: 10.1111/j.2044-8341.1959.tb00467.x.

[34] Saunders JB, Aasland OG, Babor TF, de la Fuente JR, Grant M. Development of the alcohol use disorders identification test (AUDIT): WHO collaborative project on early detection of persons with harmful alcohol consumption-II. Addiction 1993;88:791-804. doi: 10.1111/j.1360-0443.1993.tb02093.x.

[35] Picot S], Youngblut J, Zeller R. Development and testing of a measure of perceived caregiver rewards in adults. J Nurs Meas 1997;5:33-52.

[36] Zigmond AS, Snaith RP. The hospital anxiety and depression scale. Acta Psychiatr Scand 1983;67:361-370. doi: 10.1111/j.1600-0447.1983.tb09716.x.

[37] Cunha JA. Manual da Versão em Português das Escalas Beck: BDI, BAI, BHS e BSI. São Paulo, Brazil: Casa do Psicólogo; 2001.
[38] Lipp MN. Manual do Inventário de Sintomas de Stress de Lipp. São Paulo, Brazil: Casa do Psicólogo; 2000.

[39] Spielberger CD, Gorsuch RL, Lushene PR, Vagg PR, Jacobs AG. Manual for the State-Trait Anxiety Inventory. Palo Alto, CA: Consulting Psychologists Press; 1983.

[40] Rodrique JR, Jackson SI, Perri MG. Medical coping modes questionnaire: factor structure for adult transplant candidates. Int J Behav Med 2000;7: 89-110. doi: 10.1207/S15327558IJBM0702 1.

[41] Vitaliano PP, Russo J, Young HM, Becker J, Maiuro RD. The screen for caregiver burden. Gerontologist 1991;31:76-83. doi: 10.1093/geront/31.1.76.

[42] Crowne DP, Marlowe D. A new scale of social desirability independent of psychopathology. J Consult Psychol 1960;24:349-354. doi: 10. 1037/h0047358.

[43] Ware JE, Kosinski M. Improvements in the content and scoring of the SF-36 Health Survey, Version 2, 2007.

[44] Ware JE, Kosinski M, Dewey JE. How to score Version 2 of the SF-36 Health Survey. Lincoln, RI: QualityMetric Inc., 2000.

[45] Frisch MB. Quality of life inventory (QOLI). Minneapolis, MN: National Computer Systems, 1994

[46] McNair D, Lorr M, Droppelman L. Manual for the profile of mood states. San Diego, CA: Educational and Industrial Testing Service, 1981.

[47] Rodrigue JR, Baz MA. Waiting for lung transplantation: quality of life, mood, caregiving strain and benefit, and social intimacy of spouses. Clin Transplant 2007;21:722-727. doi: 10.1111/j.1399-0012.2007.00729.x.

[48] Miller RS, Lefcourt HM. Miller social intimacy scale. In: Corcoran K, Fischer ] eds. Measures for clinical practice: A sourcebook, 3rd edn. NY: Free Press, 2000: 469.

[49] Ren H, Yu Y, Hu JY, Shi Y, Lu YH, Meng W. Caregiver burden and its determinants among family members of patients with chronic viral hepatitis in Shanghai, China: a community-based survey. BMC Infect Dis 2014;14:82. doi: 10.1186/1471-2334-14-82.

[50] Pérez-San-Gregorio MÁ, Martín-Rodríguez A,. Borda-Mas M, AvarguesNavarro ML, Pérez-Bernal J, Gómez-Bravo MÁ. Family caregivers of liver transplant recipients: Coping strategies associated with different levels of post-traumatic growth. Transplant Proc 2018;50:646-649. doi: 10.1016/j. transproceed.2017.09.067.

[51] Wright J, Elwell L, McDonagh JE, Kelly DA, Wray J. Parents in transition: Experiences of parents of young people with a liver transplant transferring to adult services. Pediatr Transplant 2017;21:e12760. doi: 10.1111/petr. 12760.

[52] Zarit SH, Todd PA, Zarit JM. Subjective burden of husbands and wives as caregivers: a longitudinal study. Gerontologist 1986;26:260-266. doi: 10. 1093/geront/26.3.260. 